DOI 10.20396/temáticas.v21i41.11497

\title{
SOBRE A CIÊNCIA DO ESTADO ${ }^{1 *}$
}

\author{
Pierre Bourdieu, Olivier Christin, Pierre-Étienne Will*
}

Por mais consideráveis que sejam as conquistas das investigações históricas ou dos trabalhos de comparativistas ${ }^{2}$ que foram realizados, ao longo de muitos anos, sobre a formação e o funcionamento das burocracias de Estado, sobre suas estratégias de legitimação e sobre seus instrumentos

* O artigo foi publicado originalmente na revista Actes de la recherche en sciences sociales. Vol. 133, Juin 2000. pp. 3-11, com o título de "Sur la science de l'État". Agradecemos aos professores Olivier Christin e Pierre-Étienne Will por terem gentilmente nos autorizado a publicar essa tradução.

** Olivier Christin é professor de História Moderna da Universidade de Neuchâtel, na Suíça. É autor de diversos livros, entre os quais figuram La Paix de religion: l'autonomisation de la raison politique an XV Te siècle (Paris, Le Seuil, 1997) e Les yeux pour le croire: les Dix commandements en image (XVe-XVIIe siècle) (Paris, Le Seuil, 2003).Pierre-Étienne Will é professor de História da China Moderna no Collège de France. Entre os seus livros encontra-se Bureaucratie et famine en Chine au 18e siècle (Paris/La Haye,EHESS/Mouton, 1980) e La Chine et la démocratie: tradition, droit, institutions (em coautoria com Mireille Delmas-Marty, Paris, Fayard, 2007).

${ }^{1}$ Este número é o resultado de trabalhos que foram organizados na Fondation Hugot du Collège de France, em Junho de 1998 e Setembro de 1999, reunindo historiadores, sinólogos e sociólogos, com o propósito de evocar os impasses e dificuldades de uma história comparada, interdisciplinar e intercultural da gênese e da organização de Estados. Participaram desses encontros: Étienne Anheim, Pierre Bourdieu, Jérôme Bourgon, Patrick Champagne, Christophe Charle, Olivier Christin, Gilbert Dagron, Vincent Denis, Jean-Philippe Genet, Christian Lamouroux, Remi Lenoir, Yann Potin, Pierre Rimbert, Daniel Roche, Michel Senellart, Gilles Veinstein, PierreÉtienne Will, R. Bin Wong.

${ }^{2}$ Particularmente Charles Tilly, Coercion, Capital and European States, AD 990-1990, Oxford, 1990, que insere, na sua obra, análises sobre a China. Ver Jean-Philippe Genet (org.), L'État 
conceituais e materiais específicos, imensos problemas permanecem postos de tal modo que não podemos realmente tratar certas ilusões historiográficas a não ser na condição de abandoná-las, ao menos parcialmente. A primeira é a interpretação teleológica que descreve a emergência do Estado como um processo ininterrupto de "modernização" - ou seja, para precisar o obscuro pelo mais obscuro, o vago pelo mais vago - de "racionalização" e de "secularização", obedecendo a uma espécie de impetus natural e não às escolhas historicamente determinadas de agentes históricos específicos. Sendo assim, em État et Nation dans l'bistoire de l'Europe ${ }^{3}$, Hagen Schulze, por exemplo, confere ao Estado o estatuto de uma pessoa coletiva, dotada de uma natureza, de uma vontade e quase que de uma palavra: o Estado "recusa" a concentração de poderes nas mãos do soberano (p. 30), "organiza-se para ser onipresente" (p. 75) e "penetra" inclusive nos meios econômicos (p. 75). A custo de uma personificação similar dos coletivos, podemos descrever o Estado numa perspectiva finalista e, casando os interesses do próprio Estado, identificar o absolutismo e o progresso necessário ${ }^{4}$ a monarquia de Luís XIV “era o modelo de sucesso estatal que todos os europeus tinham vislumbravam por volta de 1700. Certamente, o modelo absolutista não era perfeito; a distância entre os sonhos de um Bodin ou de um Hobbes e a França real de Luís XIV era considerável". Em poucas palavras: a oposição entre o Estado e o "país real", o primeiro representando a inovação, o progresso, a reforma e o segundo, a inércia, a tradição, o conservadorismo; mas também a fascinação pelo "modelo" francês, suposto objeto de admiração para os Europeus.

Tendo assim inventado inteiramente uma "modernidade estatal" e um caminho único para alcançá-la, sobre o qual diferentes sistemas políticos teriam caminhado, mais ou menos rápido, atrás da França ${ }^{5}$, certos historiadores puderam, por exemplo, perguntar-se, com uma falsa candura, porque a dita

moderne: genèse. Bilans et perspectives, anais do colóquio Septembre 1989, Paris, CNRS, 1990. Ver também a publicação pelas PUF [Presses Universitaires de France] de vários volumes provenientes do programa da Fundação europeia da ciência sobre "as origens do Estado moderno na Europa".

${ }^{3}$ Tradução francesa, Paris, Le Seuil, 1996.

${ }^{4}$ Ver a crítica de J. H. Elliot, "A Europe of composite monarchies", em Past and Present, 1992.

${ }^{5}$ Seguimos, aqui, Osvaldo Raggio, "Visto dalla periferia. Formazione politiche di anticho 
"modernidade estatal (...) encarna-se nas monarquias da Europa Ocidental" e não na Polônia ou na Alemanha, omitindo (deliberadamente?) as repúblicas urbanas (como Genebra ou Berna), a Itália ou, melhor ainda, os Países Baixos do século XVII ${ }^{6}$, sem falar na China, projetando sobre o Antigo Regime a definição de Estado que é a da ciência política contemporânea. Análises como a de Rousseau, que veem na Suíça, nas Províncias Unidas dos Países Baixos e, mais ainda, no Sacro Império alemão, modelos de equilíbrio de poderes assegurados pelo direito e exemplos propícios a uma modernização política da Europa ${ }^{7}$ foram ocultados com o triunfo da historiografia nacional ou nacionalista do século XIX, que fez do Estado-nação a forma acabada da história do Estado.

Outra ilusão, herdada da teoria neoliberal, quer ver no Estado apenas o agregado instável de estratégias individuais e o conjunto de interesses particulares, esquecendo, frequentemente, que aqueles que se servem do Estado são também aqueles que o servem e que somente podem fazê-lo invocando valores comuns e interesses coletivos. Sem dúvida, nada o sugere mais claramente que a importância de noções centrais do discurso burocrático como a de "serviço", que cessa, progressivamente, de designar uma relação pessoal, de tipo feudal, para revestir-se de uma significação abstrata e geral como na expressão "serviço público": a legitimidade do agente do Estado se desloca, assim, da fidelidade ao soberano para o bem-estar comum da população.

regime e Stato moderno", em Maurice Aymard (org.) Storia d'Europa. L'età moderna: secoli XVI-XVIII, Turin, Einaudi, 1995, p. 483-527, que contesta o uso do conceito de Estado e advoga em favor de uma história menos etnocêntrica.

${ }^{6}$ Como o faz Jean-Marie Le Gall em uma nota na revista Histoire, Économie, Société, AbrilJunho, 1998.

${ }^{7}$ Jean-Jacques Rousseau, Extrait du projet de paix perpétuelle de Monsieur de Saint-Pierre, in "CEvres complètes", Paris, Gallimard, coll. "La Pléiade", t. 3, p. 572: "Assim, o direito público que os alemães estudam com tanto cuidado é ainda mais importante do que pensam e não é somente o direito público germânico, mas, de certo modo, o de toda a Europa“. Ver Fred E. Schrader, L'Allemagne avant L'État-Nation. Le corps germanique 1648-1806, Paris, PUF, coll. "Perspectives germaniques", 1998, p. 60 et seg.

${ }^{8}$ Alain Rey (org.), Le Robert. Dictionnaire historique de la langue française, Paris, 1992, sublinha bem a evolução de "serviço" e a aparição, aproximadamente em 1580, do sentido de obrigação dirigida à coletividade; a expressão "serviço público", que designa "instituições administrativas, missões de interesse geral", parece datar de 1835. 
A aparição da noção de "polícia", na Alemanha do fim da Idade Média, atesta, igualmente, essa evolução profunda da representação dos fins do Estado e do papel do soberano, cujos encargos doravante ultrapassam, de longe, a mera administração da justiça e a conservação da paz ${ }^{9}$. Particularmente entre os séculos XVI e XVIII, tanto na França quanto na Alemanha, o termo não possui, de forma manifesta, somente o sentido de manutenção da ordem, mas, sobretudo, o de "boa polícia" [bonne police]; ele tem lugar numa economia moral cristã direcionada ao Estado de bem-estar, no seio do qual o soberano deve assegurar conforto, segurança, alimentação aos seus súditos. Para um dos grandes teóricos do cameralismo do século XVIII, Johann Heinrich Gottlob von Justi ${ }^{10}$, por exemplo, a ciência da polícia deve permitir "conservar e ampliar a força geral do Estado na sua organização interna, de tal maneira que ela concorra, o máximo possível, para a felicidade comum"11.

Mesmo que a arquitetura conceitual seja em parte diferente, e que a cronologia não seja a mesma, encontramo-nos muito próximos, na outra extremidade da Eurásia, do desenvolvimento chinês. A economia moral confuciana também é voltada ao Estado de bem-estar. Desde a Antiguidade pré-imperial, de fato, a segurança econômica é concebida como inseparável do progresso moral do "povo" e da sua lealdade ao soberano (a hierarquia entre moralidade e lealdade varia, acompanhando as filosofias - e aqui a Antiguidade chinesa oferece um mélange surpreendente $)^{12}$. A indissociabilidade da "educação" e da "alimentação" está o fundamento de uma filosofia política que é imposta suficientemente rápido, à despeito das origens sobretudo

\footnotetext{
${ }^{9}$ Michael Stolleis, Histoire du doit public en Allemagne. Droit public impérial et science de la police 1600-1800, tradução francesa, Paris, PUF, 1998, p. 558 et seg, e Polizei im Europa der Frühen Neuzeit, Frankfurt, Klostermann, 1996.

${ }^{10}$ 1717-1771. Ver a definição de cameralismo de Konrad Fuchs e Heribert Raab, Wörterbuch zur Geschichte, Munique, DTV, 10ª edição, 1996: "Forma tardia do mercantilismo alemão que tem por objetivo resultar numa Staatswirtschaft ("economia de Estado") num dado território. A "cameralística" ocupa-se assim, por vezes, de teoria administrativa ou econômica, direito e finanças públicas.

${ }^{11}$ Citado por Michael Stolleis, Histoire du droit public en Allemagne, p. 574-575.

${ }^{12}$ Encontraremos a introdução mais adequada a essa variedade na nova edição de Sources of Chinese Tradition, vol. 1, organizado por Wm. Theodore de Bary e Irene Bloom, New York, Columbia University Press, 1999.
} 
tecnocráticas e policialescas da primeira unificação imperial, no século III a.C.. Com o passar do tempo, instalam-se autênticas instituições de bem-estar social, assim como uma ética burocrática do serviço público, que se distingue, bastante nitidamente, do serviço do soberano, mesmo que a separação teórica entre os dois jamais tenha sido verdadeiramente consumada no Antigo Regime ${ }^{13}$. Essa mutação, se for necessário datá-la, remonta à construção do Estado civil e burocrático dos Sung, no século X, que será, várias vezes, tema das páginas subsequentes; e é bem conhecido que a sinologia europeia dos séculos XVII e XVIII deu grande importância a essas instituições de bem-estar social, como a dedicação exclusiva à felicidade dos povos que ela atribuía aos "mandarins". Quanto à noção citada há pouco, de uma ciência da polícia (a "gestão da sociedade", como dizem os chineses) visando o aumento da força do Estado a fim de concorrer para o bem comum, ela está, mais do que nunca, presente numa China moderna, onde o discurso liberal anti-estatal nunca teve muita adesão.

Lá, como aqui, existem, portanto, muitos valores burocráticos específicos, encarnados neste ethos da dedicação e do desinteresse, que estão no fundamento da identidade coletiva dos "servidores do Estado". Há também os interesses burocráticos específicos que se manifestam na produção de verdadeiras ficções administrativas, na invenção de representações originais do mundo social por exemplo, através das taxonomias fiscais ou da oposição entre "nacionais" [ressortissants nationaux] e estrangeiros - ou ainda na fabricação de "problemas de sociedade" que existem, de início, e às vezes somente por e para os agentes do Estado que os formulam, expõem-nos, afrontam-nos, pretendem

\footnotetext{
${ }^{13}$ A crítica radical da autocracia, acusada de ter afastado do serviço do povo a burocracia e as instituições de Estado e de ter feito, tanto de uma quanto das outras, um monstro tecnocrático desconectado de valores morais, exclusivamente consagrado à pilhagem dos recursos do império para proveito do soberano e de sua casa [maison], apenas encontra-se realmente na segunda metade do séc. XVII num pequeno número de pensadores brilhantes, mas isolados, tais como Gu Yanwu (1613-1682) ou Huang Zongxi (1610-1695). Sobre o primeiro, retomar as observações de Jacques Gernet in Annuaire du Collège de France, anos 1983-1984 e 1984 1985; para o segundo, ver Wm. Theodore de Bary (tradução e apresentação), Waiting for the Dawn. A Plan for the Prince: Huang Tsung-hsi's Ming-i tai-fang lu, New York, Columbia University Press, 1993.
} 
resolvê-los: o abandono da agricultura "útil" de subsistência ou o sucesso das religiões heterodoxas na China pré-moderna, a invasão dos pobres na época moderna ou a "crise das periferias [banlieues]" hoje.

\section{UMA LITERATURA SEM AUTORES}

Adotar uma perspectiva comparativa e interdisciplinar era também repudiar uma história do Estado que, ao aceitar a divisão desastrosa entre a história das ideias e a história social, e a divisão correlata entre a filosofia política e a prosopografia das "elites" administrativas e políticas, impede de buscar em que essas "elites", por vezes obscuras, contribuíram para transformar as representações do Estado e de suas funções, desenvolvendo uma ciência anônima e prática da administração e dos fins e meios do Estado, jus publicum, organização dos arquivos e de tudo que designamos hoje pelo nome de "literatura cinza", organogramas, regulamentos internos, memorandos etc. Sem dúvida, o desenvolvimento do Estado é acompanhado de um intenso trabalho teórico de justificação, de explicitação ou de contestação, no contexto do qual emergem alguns grandes nomes sempre citados (Maquiavel, Bodin, Hobbes, Locke, para a tradição europeia). E os trabalhos de Quentin Skinner particularmente, mas também de muitos outros autores, contribuíram, nos últimos vinte anos, para renovar profundamente a história da filosofia política, liberando-a das análises anacrônicas ou puramente acadêmicas dos grandes textos canônicos, retomando as meticulosas apostas históricas nas quais os teóricos do político se encontravam confrontados e recordando sua posição pessoal no seio das instituições estatais, permitindo, por meio disso, enfim, ler os grandes textos da Idade Média ou da época moderna como manifestos ou programas concebidos pelos atores da construção do Estado e não como manuais ou descrições objetivas das instituições ${ }^{14}$.

\footnotetext{
${ }^{14}$ Ver, particularmente, Quentin Skinner, The Foundations of Modern Political Thought, Cambridge, Cambridge University Press, 1980. Sobre as escolhas metodológicas de Skinner e sua ruptura com uma certa tradição da história da filosofia, ver James Tully (org.), Meaning and Context: Quentin Skinner and his Critics, Cambridge, Polity, 1988.
} 
Justamente, a própria ideia de filosofia política ou de escritos teóricos sobre o Estado parece demasiado limitadora para compreender plenamente a importância desse "trabalho do Estado sobre ele mesmo", de que falava Denis Richet ${ }^{15}$. A particularidade do Estado burocrático é a de ter suscitado uma inflação documentária sem precedentes, uma proliferação arquivística que os historiadores muito buscaram, sempre sem se questionar a respeito das condições intelectuais e materiais da sua produção e da sua conservação. As burocracias europeias, chinesas, otomanas, engendraram, assim, uma literatura particular e particularmente abundante que não se permite reduzir à categoria de escritos sobre o Estado ou de tratados políticos. Frequentemente anônima e técnica, por vezes redigida numa linguagem codificada mais ou menos inacessível aos profanos, ela está, no entanto, longe de ser desprovida de tudo que está em jogo do ponto de vista teórico, e veicula representações do Estado que são constitutivas da própria realidade do Estado porque elas contribuíram de maneira durável para sua formação e transformação, e porque foram tão mais eficazes que pareciam obedecer somente às considerações práticas.

Michael Stolleis mostrou, assim, que a emergência dos Estados territoriais modernos na Alemanha protestante logo após a Paz de Augsburgo (1555) é inseparável de um trabalho intenso de reflexão sobre os fins e os meios específicos da força pública ${ }^{16}$. Com a divisão religiosa definitiva entre católicos e luteranos, tudo, ou quase tudo, é posto, com efeito, a repensar ${ }^{17}$ : o caráter sagrado do Império, as relações entre poderes espirituais e temporais, o destino dos bens da igreja secularizados, as relações entre Estados e o lugar do direito nelas. Os progressos do Estado burocrático então se confundem, em parte, com a rápida constituição de uma nova disciplina, o jus publicum, que se estrutura ao redor de ensinamentos, escolhas lexicais, interesses teóricos e

\footnotetext{
15 “La monarchie au travail sur elle-même?”, comunicação de 1986, retomada na coleção de artigos De la Réforme à la Révolution. Études sur la France moderne, Paris, Aubier, 1991, p. $425-450$.

${ }^{16}$ Michael Stolleis, Histoire du droit public en Allemagne, Op. Cit., passim.

${ }^{17}$ Sobre essa questão, ver Olivier Christin, La Paix de religion. L'autonomisation de la raison politique au XVI e siècle, Paris, Le Seuil, 1997.
} 
problemas práticos comuns, e oferece aos príncipes novos instrumentos conceituais de governo e legitimação sob a forma de inúmeras publicações, teses, disputas, enciclopédias, compilações de leis, mas também de intervenções diretas de especialistas no seio das instâncias do poder. Conscientes dos lucros simbólicos e das vantagens concretas que eles podem extrair desse reordenamento de saberes sobre o Estado, os príncipes europeus multiplicam as criações de cadeiras universitárias e encorajam as publicações intelectuais [savantes]. Sem consciência disso, é claro, eles seguem o caminho dos príncipes chineses dos tempos pré-imperiais que encorajavam e recrutavam pensadores, estrategistas e tecnocratas à espera de que eles aumentassem sua força e seu reinado num contexto de competição entre Estados; do mesmo modo como eles seguem o dos autocratas dos séculos mais recentes que patrocinavam a erudição acadêmica e custeavam a compilação de enciclopédias institucionais para consolidar a legitimidade de seus regimes.

Ler ou reler essas inúmeras obras, frequentemente obscuras, voltar às condições históricas nas quais se inserem é, sem dúvida, munir-se dos meios para compreender melhor o que está verdadeiramente em jogo em alguns dos mais célebres e mais celebrados textos da filosofia ou da teologia políticas, ou mesmo da literatura, escritos precisamente contra essa literatura cinza e contra os detentores de competências técnicas que pretendem exercer uma influência decisiva sobre o Estado. Sem retomar demoradamente os afrontamentos ocorridos entre legistas, juristas, filósofos e teólogos, objetos de sólidos trabalhos, pode-se assumir que a afirmação da razão burocrática e a conquista de posições-chave no seio dos Estados pelos técnicos da coisa pública suscitam advertências e críticas recorrentes, cuja história permanece por fazer. Particularmente para a Europa dos séculos XVI e XVII, como não levar em consideração Lutero - que vê em cada jurista um mau cristão, trocado, então, por inúmeras folhas voantes e gravuras -, ou Rabelais e sua ilha de "Chicanous", ou ainda os Plaideurs, e como não aproximar essas desqualificações simbólicas das transformações que então afetam os Estados e, sobretudo, da promoção dos profissionais do direito ${ }^{18}$, da multiplicação dos cargos públicos,

${ }^{18}$ Ronald Schnur, Die Rolle der Juristen bei der Entstehung des modernen Staates, Berlin, 1986.

Temáticas, Campinas, 20(41): 000-000, ago./dez. 2012 
passados de 5.000, na França do início do século XVI, a cerca de 50.000 por volta de 1660 e, ainda na França, da progressão da venalidade legal dos cargos públicos ${ }^{19}$ ? E, mutatis mutandis, encontramos o mesmo gênero de maldição em uma China onde a função pública não cessa de expandir sua empresa e de se tecnicizar, de modo particularmente espetacular nos séculos X e XVIIIXIX, por exemplo - à exceção de que, no primeiro caso, trata-se de uma vontade deliberada de expansão do Estado, de suas intervenções e de seus rendimentos, que veio do alto (as famosas reformas do primeiro ministro Wang Anshi, por volta de 1070, cristalizaram o mau humor de gerações de letrados, praticamente até o fim do período imperial); enquanto que, no segundo, essa expansão se deu, num certo sentido, a partir de baixo, sob as características de uma proliferação não controlada e, em boa parte, ilegal, do pessoal subalterno, atraído pela crença econômica e demográfica do império e do aparelho regulamentar.

A intenção comum às diferentes contribuições reunidas aqui é a de submeter essa produção burocrática imensa, mas pouco conhecida, a uma leitura histórica e sociológica, é a de levar a sério a prosa administrativa, os novos gêneros retóricos forjados na prática cotidiana dos agentes do Estado, dos gabinetes, das comissões, das assembleias: o relatório, a circular [circulaire], o formulário, que impõe a inserção de informações de caráter pessoal dentro de uma trama impessoal e padronizada, a ficha de avaliação... Trata-se aqui, sem dúvidas, de um desafio considerável, mas isso deve permitir, em alguma margem de tempo, que não se confunda mais as representações ideais e, em grande medida, imaginárias, que o Estado, por intermédio de alguns de seus teóricos apontados, quis dar a si mesmo, e à realidade das práticas intelectuais, das formas de pensamento e de ordenação do mundo, das rotinas burocráticas pelas quais ele se forma, se perpetua, se legitima dia após dia e garante o que

\footnotetext{
${ }^{19}$ Robert Descimon, "Modernité et archaïsme de l'État monarchique: le Parlement de Parissaisi par la vénalité (XVIe siècle)", in Jean-Philippe Genet (org.) L'État moderne: genèse, Op. Cit., p. 147-161, e, sobretudo, "La vénalité des offices et la construction de l'État dans la France moderne. Des problèmes de la représentation symbolique aux problèmes du coût social du pouvoir", in Robert Descimon et al., Les Figures de l'administrateur. Insitutions, réseaux, pouvoirs en Espagne, en France et au Portugal XVIe-XIXe siècle, Paris, EHESS, 1997, p. 7793 .
} 
se chama, hoje, a continuidade do Estado. Tradicionalmente, tomamos o exemplo do correio para ilustrar a confiança implícita na continuidade do mundo natural e do mundo social que nos anima nos gestos mais inofensivos: colocar uma carta no correio é acreditar que alguém virá pegá-la para expedila, que o selo ainda estará valendo, que os transportes funcionarão bem, que o destinatário estará vivo ainda... Qual crença na perenidade de um Estado, no entanto, longínquo e frequentemente ausente, compartilham então, no fim da idade média e durante a Europa moderna, aqueles que se acostumam, pouco a pouco, a pagar impostos regulares e a regularizar suas contendas por via da justiça - como o faziam há muito seus semelhantes na Ásia oriental -, ou a clamar ao soberano que "salve sua vida", ou a morrer pela pátria ${ }^{20}$ ? A característica própria do trabalho burocrático de invenção de rotinas e de procedimentos foi, assim, talvez a de dar um sentido concreto, cotidiano, à ideia de continuidade do Estado abaixo das sábias [savantes] construções teológico-políticas que a fundaram.

\section{SABERES BUROCRÁTICOS}

Se a expressão "ciência do Estado" pareceu exprimir de maneira suficientemente precisa e concisa o sentido desse projeto de pesquisa comparativa, é porque não se trata tanto de fazer uma história das teorias do Estado que acompanharam o desenvolvimento das instituições estatais e a reflexão sobre seus fins legítimos, mas de compreender o que está em jogo na produção, por parte dessas instituições, de uma imensa ciência prática da força pública. Em primeiro lugar, os administradores e os agentes da força pública devem forjar as ferramentas conceituais e materiais impostas pela extensão progressiva dos interesses e, portanto, das intervenções do Estado. Na Europa moderna (entre os séculos XVI e XVIII), por exemplo, o Estado se preocupa,

\footnotetext{
${ }^{20}$ Ernst H. Kantorowicz, "Pro patria mori in medieval political thought", in The American History Review, n. 56, 1951, p. 472-492, e Philippe Contamine, "Mourir pour la patrie, XeXXe siècle", in Pierre Nora, Les Lieux de mémoire, t. II, La Nation, Paris, Gallimard, 1986, p. $11-43$.
} 
de maneira progressiva, em avaliar a população precisamente, em distinguir seus nacionais [ressortissants] daqueles que não estão submissos diretamente à sua jurisdição, em mensurar a atividade econômica ou, ao menos, os movimentos dos preços e a circulação de mercadorias e de capitais. É assim que aparecem as primeiras estimativas demográficas - inicialmente limitadas e subordinadas a objetivos essencialmente fiscais -, posteriormente as experiências de recenseamento, mas também as pesquisas econômicas, as descrições sistemáticas dos recursos de tal e tal país, as tabelas numeradas possuindo, ao mesmo tempo, a exaustividade e a homogeneização dos dados coletados. O crescimento das competências de que se apropriam os Estados europeus modernos é acompanhado, assim, pela invenção de instrumentos inéditos e das novas ciências que, sendo essencialmente os produtos da atividade dos administradores e das instituições públicas, revelam e legitimam a ideologia implícita: a economia política, a estatística, a demografia, o cameralismo ${ }^{21}$. Intimamente ligadas, em sua origem, aos interesses específicos do Estado, implementadas, ao mesmo tempo, pelos intelectuais [savants] e pelos administradores, ou pelos funcionários-tecnólogos, rapidamente formados nas escolas especializadas, cujos primeiros exemplos na França aparecem no século XVIII ${ }^{22}$, essas novas disciplinas contribuem fortemente para justificar a ação da burocracia: "O grande instrumento de superioridade da administração burocrática é o saber especializado" 23 . Elas aceleram a transformação do modo de recrutamento dos agentes do Estado, substituindo progressivamente a recomendação ou a proteção pessoais e a formação "na prática do trabalho"

\footnotetext{
${ }^{21}$ Ver, para essas ciências do Estado, Jean-Claude Perrot, Une histoire intellectuelle de l'économie politique, Paris, EHESS, 1992; Éric Brian, La Mesure de l'État. Administrateurs et géomètres au XVIIIe siècle, Paris, Albin Michel, 1994; de vários autores, Pour une histoire de la statistique, t. 1: Contributions, Paris, Économica/INSEE, 1977, reeditado em 1987; P. Schiera, Dall'arte di governo alle scienze dello Stato. Il cameralismo et l'assolutismo tedesco, Milão, 1968, La concezione amministrativa dello Stato in Germania (1550-1750), Turim, 1980.

${ }^{22}$ Particularmente no caso dos geógrafos e topógrafos; ver Antoine Picon, L'Invention de l'ingénieur moderne. L' École des Ponts et Chaussées, 1747-1851, Paris, ENPC, 1992. \} É preciso levar em consideração, nos mesmo anos, a criação da Escola da Marinha [École de la marine] e da Escola de Engenharia de Minas [a tradução é extra-oficial, a instituição chamavase École du génie de Mézières].

${ }^{23}$ Max Weber, Économie et société, Paris, Plon, 1971, p. 229.
} 
[sur le tas] pela seleção escolar, o concurso, a prova, legitimando, assim, a dominação das normas burocráticas sobre a competência técnica especializada e as "limitações" dessa competência que dela resultam e que são, em grade medida, incorporadas nas disposições dos "intelectuais de Estado".

É aqui, aliás, que a comparação com a experiência chinesa parece particularmente sugestiva e convida, também, a novas reflexões. Em seus esforços para adotar uma melhor medida de sua população, dos parâmetros da atividade econômica e dos recursos de diferentes regiões, os Estados europeus da época moderna acompanham, se é possível dizer assim, uma venerável tradição chinesa associada, corriqueiramente, com o que se convencionou chamar de "legista". Tradição representada, de maneira muito irregular, seguindo os regimes e as épocas, é certo, da qual vimos para além do que ela tinha de má reputação diante da opinião letrada dominante e sobre a qual não é desinteressante constatar que ela conheceu um ressurgimento espetacular o bastante, ainda que camuflado sob as roupas [oripanx] do mais conforme humanismo confuciano, no século XVIII - como na Europa. Mas, a despeito dos paralelos interessantes, a Europa foi, com grande rapidez, muito mais longe na criação de autênticas "ciências" sociais, postas a serviço do Estado, incontestavelmente mais sofisticadas, legitimadas como "especialidades" e de onde vêm, pelo caminho mais curto, aquelas que, hoje, gerem ou procuram gerir os Estados do mundo inteiro: a demografia, a estatística e a economia política que são ensinadas, já faz um século, na China são as da Europa e da América; elas não dão continuidade às disciplinas paralelas elaboradas pela tradição intelectual chinesa.

\section{CONTROLAR-SE PARA MELHOR CONTROLAR}

Outro aspecto dessa "ciência prática": contra a multiplicidade de críticas que lhe denunciam a força, a obscuridade, a corrupção e muitos outros vícios ainda, as burocracias de Estado procuram começar, muito rapidamente, a se defender à medida que pretendem controlar-se a si mesmas. Uma das atividades essenciais das burocracias modernas torna-se, assim, a de vigiar e de avaliar seus próprios agentes e suas próprias ações. Há, certamente, 
precedentes e paralelos, especialmente na igreja católica com, por exemplo, a prática das visitas pastorais nas quais o bispo, ou seu vigário, examina as edificações e os objetos do culto, mas afere também os párocos e os padres [desservants] locais. Na China, o regime Ming (1368-1644) instaurou o sistema extraordinário dos "censores itinerantes", um corpo de funcionários relativamente jovens, escolhidos, em princípio, em meio aos mais qualificados ideologicamente e moralmente, que purificavam, literalmente, as províncias que lhes eram delegadas com plenos poderes para tudo inspecionar, tudo denunciar e tomar, eles mesmos, múltiplas iniciativas ${ }^{24}$. Os eunucos do palácio ou, sob os Qing, os Manchu, anexados à casa imperial, por vezes desempenharam um papel comparável ao de missi dominici. Mas, no fim da época imperial, a fórmula dominante é a vigilância da burocracia por ela mesma, por um jogo de avaliações muito formalizadas e de "garantias" (isto é, de não-delinquência) em cascata, de alto a baixo na hierarquia, cujos efeitos perversos são fáceis de imaginar quando se sabe que controladores e controlados dependiam financeiramente uns dos outros e que a objetividade tendia, em consequência disso, a ceder à "proteção", em detrimento, particularmente, dos grande imperadores Manchu, que parecem, às vezes, ter estado entre os primeiros depreciadores de sua própria burocracia.

O Estado europeu moderno incita, inversamente, a lógica do controle interno no seu limite, dando origem a instituições especializadas no trabalho de avaliação, de notação, de controle. Os intendentes de polícia, justiça e finanças, dos quais a historiografia faz, há muito, um dos símbolos do triunfo do absolutismo na França, são, assim, recrutados no seio de corpos específicos de oficiais e dotados, pelo rei, de cartas de comissão que os encarregam, entre outras atividades, de vigiar os oficiais locais. Segundo uma fórmula do século XVII, por exemplo, eles devem "conhecer todas as injustiças e opressões que os súditos do rei poderiam sofrer dos oficiais e ministros por corrupção, negligência, ignorância, ou de outro modo" ${ }^{25}$. Nesse sentido, os intendentes

\footnotetext{
${ }^{24}$ Ver Charles O. Hucker, The Censorial System of Ming China. Stanford, Stanford University Press, 1966.

${ }^{25}$ Citado por Marcel Marion, Dictionnaire des institutions de la France aux XVIIe e XVIIIe siècles, 1923; reeditado pela editora Picard, 1984, p. 293.
} 
representam antes o Estado burocrático impessoal que o rei nas províncias ${ }^{26}$. A vigilância burocrática da burocracia se torna, assim, ao mesmo tempo uma das justificativas essenciais da burocracia, mas também uma das condições de seu crescimento institucional e demográfico. A vontade de avaliar os serviços e os méritos dos agentes do Estado conduz também, em certas ocasiões, a finalizar formulários ou fichas individuais, ou mesmo verdadeiros sistemas de notação. Como na China, aliás, essas técnicas de gestão do pessoal administrativo definem os perfis ideais dos servidores do Estado ${ }^{27}$ e contribuem para projetar os currículos regulares, precisos, codificados, que estabelecem regras de recrutamento, de avanço, de mutação, criando, assim, um espírito de equipe no seio das diferentes instituições ${ }^{28}$. O controle burocrático não é, portanto, em nada um limite para o poder da burocracia; ele é, até mesmo, seu fundamento.

Restaurando ao controle burocrático a partir de Max Weber, sua importância como forma específica de gestão das negociações e das pessoas e como técnica particular de legitimação, encontramo-nos confrontados com os conflitos internos que atravessam as administrações e as instituições estatais e que a análise histórica tende, frequentemente, a ignorar ou a minimizar. Não mais que o Estado, a burocracia não pode ser pensada como um coletivo unificado e reificado que poderíamos conceber como um quase-sujeito dotado de intenções e de vontades: é um espaço de jogo relativamente independente das forças econômicas e sociais, no qual os agentes nas origens, nas trajetórias, nos interesses, nos capitais (escolares principalmente) e nas competências, heterogêneas e frequentemente contraditórias, ao menos em parte se encontram e se afrontam para a própria definição da coisa pública e do serviço do Estado, compartilhando, às vezes inconscientemente, um certo número de apostas, mas também de conceitos e de métodos. Podemos ver, aqui, uma

${ }^{26}$ Ver a conclusão de Michel Antoine, "Genèse de l'institution des intendants", in Journal des savants, 1982, p. 283-317: "Nunca o intendente representou o monarca, ele não representou sequer uma pessoa, mas uma abstração: o Estado".

${ }^{27}$ Ver, aqui, Philippe Minard, La Fortune du colbertisme. État et industrie dans la France des Lumières, Paris, Fayard, 1998, p. 76 et seq.

${ }^{28}$ Ver as páginas de Jean Nagle sobre o século XVII em Marcel Pinet, Histoire de la fonction publique en France, Paris, 1993, t. I, p. 271 et seq. 
perfeita ilustração na Fronda, movimento pelo qual, em nome de uma concepção precisa de Estado, de suas funções, de sua reforma e da fidelidade ao rei, certos detentores de cargos de autoridade se revoltam contra a multiplicação dos ofícios e as transformações administrativas rápidas da monarquia engajada na exaustiva Guerra dos Trinta Anos.

De fato, a história da construção do Estado (seja da monarquia francesa ou do império chinês) não pode ser separada da história dos conflitos entre os atores que contrapõem a representação do que deve ser o Estado e o serviço da coisa pública: no caso da monarquia francesa, os adeptos tradicionais do hausehold government, no qual o essencial permanece sendo o serviço pessoal do soberano, combatem, assim, os detentores dos novos ofícios corruptíveis, que estão interessados, em todos os sentidos do termo, no bom encaminhamento de um Estado mais abstrato, do qual eles são de facto os credores; no caso da China, os funcionários titulares se opõem ao setor informal, assim como a ciência oficial dos administradores de elite se opõem à "ciência da sombra" praticada por qualquer um. O Estado moderno e a burocracia específica que aqui se impõe pouco a pouco, e não sem problemas, são, portanto, campos que se deve submeter a uma análise inseparavelmente sociológica e histórica, visando determinar as relações objetivas entre serviços e corpos que, aparecendo, às vezes, em momentos muito distantes na história, são associados a interesses frequentemente divergentes e contraditórios e se afrontam, continuamente, nos conflitos, que são um dos princípios da extraordinária inércia de todas as burocracias, mas também de sua capacidade de conservar as conquistas histórias das lutas sociais do passado.

Tradução e revisão de Danilo Arnaut e Juliana Miraldi. 